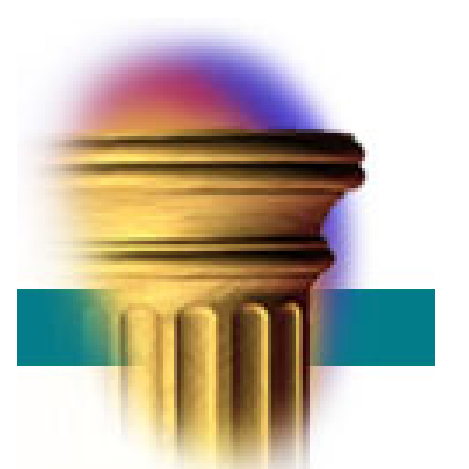

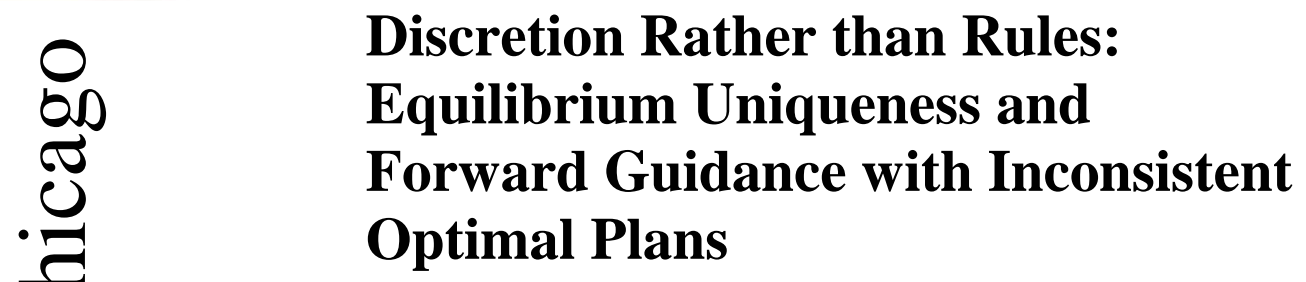

Jeffrey R. Campbell and Jacob P. Weber

\author{
REVISED \\ January 31, 2019
}

WP 2018-14

https://doi.org/10.21033/wp-2018-14

*Working papers are not edited, and all opinions and errors are the responsibility of the author(s). The views expressed do not necessarily reflect the views of the Federal Reserve Bank of Chicago or the Federal Reserve System. 


\title{
Discretion Rather than Rules: Equilibrium Uniqueness and Forward Guidance with Inconsistent Optimal Plans
}

\author{
Jeffrey R. Campbell* Jacob P. Weber ${ }^{\dagger}$
}

January 31, 2019

\begin{abstract}
New Keynesian economies with active interest rate rules gain equilibrium determinacy from the central bank's incredible off-equilibrium-path promises (Cochrane, 2011). We suppose instead that the central bank sets interest rate paths and occasionally has the discretion to change them. With empirically-reasonable frequencies of central bank reoptimization, the monetary policy game has a unique Markov-perfect equilibrium wherein forward guidance influences current outcomes without displaying a forward guidance puzzle.
\end{abstract}

${ }^{*}$ Federal Reserve Bank of Chicago and CentER, Tilburg University. Jeff.Campbell@chi.frb.org

${ }^{\dagger}$ Department of Economics, University of California at Berkeley. jacob_weber@berkeley.edu

We thank Roc Armenter, Gadi Barlevy, Bob Barsky, Marco Bassetto, Gauti Eggertsson, Jordi Galí, Simon Gilchrist, the late Alejandro Justiniano, Assaf Patir, Stephanie Schmitt-Grohé, Johannes Wieland and Michael Yang for insightful comments and discussion. Any errors that remain are our own. The views expressed herein are those of the authors. They do not necessarily represent the views of the Federal Reserve Bank of Chicago, the Federal Reserve System, or its Board of Governors.

JEL Codes: E12, E52.

Keywords: Monetary Policy, Open Mouth Operations, Quasi-Commitment, Ramsey Problem. 


\section{Introduction}

This paper replaces the interest rate rule in the three-equation New Keynesian (NK) model with benevolent central bankers who can commit to interest rate paths for random terms in office. If central bankers turn over frequently enough, then the economy has a unique symmetric Markov Perfect Equilibrium (MPE) even though each one of them commits to a completely passive interest rate rule. Simple intuition explains this result: central bankers optimize in the future, private agents optimally respond to the resulting interest rates when they are set, and the private sector takes these future outcomes as given when making current consumption and pricing decisions. This basic logic of Markov-perfect Nash equilibrium reduces the scope for self-fulfilling prophecies to influence current choices.

Our model builds upon the quasi-commitment framework of Roberds (1987), which Schaumburg and Tambalotti (2007), Bodenstein, Hebden, and Nunes (2012) and Debortoli and Nunes (2014) have previously applied to the NK model. In it, the central banker commits to a deterministic path for interest rates while facing a constant probability of being replaced by a successor who will herself reoptimize. The future interest rates along this path constitute the central banker's forward guidance.

No major central bank provides complete and perfectly credible details of its policy actions for the indefinite future. In the discussion of Campbell, Evans, Fisher, and Justiniano (2012), Donald Kohn asserted that "no central bank to date has adopted an Odyssean commitment strategy," and Laurence Meyer stated that 98 of the 100 market participants he interviewed understood forward-looking statements of the Federal Reserve to be forecasts rather than commitments (Romer and Wolfers, 2012). Therefore, the benchmark from which an empirically-useful consideration of forward guidance should deviate is closer to complete discretion than to perfect commitment. On the other hand, monetary policy committees adjust their policies slowly (Blinder, 1998), so their choices and forward guidance embody some commitment. Indeed, slow adjustment and long periods of inaction are natural features of any institutional setting where decisions have to be made by consensus. Riboni and Ruge-Murcia (2010) demonstrate how such "status quo bias" arises naturally when monetary policy committee members have heterogenous goals, and they argue that such models explain the actual behavior of central banks well. Ruge-Murcia and Riboni (2017) empirically validate this prediction with a natural experiment created by changes to the Bank of Israel's governance structure. Thus committee gridlock effectively endows a central bank with some degree of commitment, even when individual members vote with discretion (Riboni, 2010).

We interpret our model's central banker replacement as a metaphor for considerations which could lead committees of central bankers to renege on their prior commitments, and 
quasi-commitment represents this commitment "technology" in an analytically tractable way. Our implementation of quasi-commitment abstracts from central bankers' freedom to respond to non-contractable but relevant variables, as discussed by Kocherlakota (2016). Nevertheless we believe that the quasi-commitment framework represents monetary policy formation more realistically than the standard interest rate rule, which also abstracts from many observable variables used by central bankers in practice. While such rules describe observed central bank behavior conditional upon very limited information sets well, their embodiment within the NK model imposes the incredible off-equilibrium-path promises detailed by Cochrane (2011).

Our work is related to many other examinations of equilibrium multiplicity in the NK model. Adão, Correia, and Teles (2011) gain equilibrium uniqueness with a passive interest rate rule which exactly cancels out forward looking terms in the IS curve; unlike those authors, we have central bankers choosing deterministic paths for interest rates. Adão, Correia, and Teles (2014) deliver determinacy by introducing long-term debt and having the central bank manipulate bond term premiums. Our framework incorporates no deviation from the expectations theory of the term structure. Both King and Wolman (2004) and Armenter (2008) establish multiplicity of MPEs in nonlinear NK models with an inflation bias, while Siu (2008) shows that these results are sensitive to the specification of firms' nominal pricing technology. We demonstrate our result within the standard linearized NK model based on the standard Calvo pricing technology, which lacks an inflation bias. Finally, Blake and Kirsanova (2012) showed that linearized NK models with endogenous state variables, such as the stock of government debt, can have multiple MPEs. Our model's only endogenous state variables are the interest-rate commitments of incumbent central bankers. Empirically-relevant NK models include many endogenous state variables, such as capital and past wage and price inflation. Just as the Taylor principle is only suggestive of equilibrium determinacy in such environments (Coibion and Gorodnichenko, 2011), our results provide a useful baseline for the examination of DSGE models with quasi-commitment (Debortoli and Lakdawala, 2016).

Another approach to eliminating equilibrium indeterminacy and solving the forward guidance puzzle introduces discounting into the the IS curve of the standard model. Definitionally, this reduces the elasticities of current output with respect to future output and inflation. Many authors have introduced modifications to the standard model to introduce such discounting, including Del Negro, Giannoni, and Patterson (2015); Fisher (2015); McKay, Nakamura, and Steinsson (2017); Gabaix (2018); and Michaillat and Saez (2019). Campbell and Weber (2019) reviews these modifications in detail. Quasi-commitment yields equilibrium determinacy through a distinct channel. Instead of making expectations of future output and inflation less important for the present, game-theoretic considerations partially 
determine them ex ante. Simple intuition explains this result: central bankers optimize in the future, private agents optimally respond to the resulting interest rates when they are set, and the private sector takes these future outcomes as given when making current consumption and pricing decisions. This basic logic of Markov-perfect Nash equilibrium reduces the scope for self-fulfilling prophecies to influence current choices. Similarly, quasi-commitment solves the forward guidance puzzle almost by construction by reducing the power of promises, as demonstrated by Haberis, Harrison, and Waldron (2014). Though our channel introduces no discounting, as the IS curve remains unchanged, we employ some of the insights of this literature in the discussion of our results.

An older game-theoretic approach to the time-consistency problem in monetary policy characterizes all subgame perfect equilibria of the game between an infinitely-lived monetary authority and the private sector (Chari and Kehoe, 1990; Stokey, 1991; Chang, 1998; Phelan and Stacchetti, 2001). Chari, Christiano, and Eichenbaum (1998) label those equilibria with outcomes inside the policy frontier "expectation traps," and they interpret regime switches in U.S. macroeconomic performance as movements between "bad" and "good" equilibria. This approach to solving the time-consistency problem conceives of commitment as a characteristic of the solution concept: the best subgame perfect equilibrium. In contrast, we model commitment more heuristically as a technologically-given probability of the central bank keeping its promises. Therefore, we can compare economies with different amounts of central-bank commitment; which seems to us a precondition for quantitative empirical applications.

To demonstrate our framework's quantitative potential, we calculate an upper bound on the average duration of central bank commitment consistent with equilibrium uniqueness using the parameter values estimated by Galí and Gertler (1999) and other values employed by Eggertsson and Woodford (2003) and Schaumburg and Tambalotti (2007). This upper bound varies between three and eleven quarters, so the model can have both equilibrium uniqueness and nontrivial implications for forward guidance. ${ }^{1}$ Campbell and Weber (2019) note that the standard NK model's forward guidance employs an unspecified ability to coordinate expectations on one of many equilibria. Because our model has only one equilibrium given any interest rate path, its forward guidance does not depend on such "open mouth operations."

In the next section, we lay the foundations for our analysis by reviewing the Ramsey planning formulation of the central bank's problem. We then introduce quasi-commitment

\footnotetext{
${ }^{1}$ As noted above, each central banker in our model has a stochastic tenure which can be arbitrarily long. The relevant modification of our model with term-limited central bankers always has a unique Markov-perfect Nash equilibrium. However, we demonstrate in Campbell and Weber (2019) that its monetary policy advice relies excessively on the forward-guidance puzzle when these term limits are the only bounds on commitment.
} 
by temporarily assuming that the current central banker's successor returns inflation and the output gap to zero with some fixed probability in each time period, as in Schaumburg and Tambalotti (2007). In Section 3, we relax that assumption by explicitly modeling the game associated with quasi-commitment. In it, an initial central banker chooses a path of interest rates while aware that she may be succeeded in each period by another central banker who will reoptimize. We show that if the the probability of reoptimization is high enough, then the resulting unique symmetric Markov perfect equilibrium coincides with the Ramsey planning allocation under quasi-commitment. Section 4 demonstrates that the quasicommitment framework with a unique equilibrium lacks a forward guidance puzzle. Section 5 characterizes optimal forward guidance under quasi commitment facing a transitory costpush shock. Specifically, we note that promising to implement price level targeting continues to be optimal even though private agents rationally expect only partial achievement of that goal in equilibrium. Section 6 contains concluding remarks.

\section{Ramsey Planning with Quasi-Commitment}

Our analysis characterizes monetary policy for a standard NK economy. ${ }^{2}$ The economy's Phillips curve (PC) is

$$
\pi_{t}=\kappa y_{t}+\beta \mathbb{E}_{t}\left[\pi_{t+1}\right]+m_{t}
$$

with $\mathrm{PC}$ intercept $m_{0} \neq 0$ and $m_{t}=0$ for all $t>0 .^{3}$ Its intertemporal substitution (IS) curve is

$$
y_{t}=-\frac{1}{\sigma}\left(i_{t}-\mathbb{E}_{t}\left[\pi_{t+1}\right]-i^{\natural}\right)+\mathbb{E}_{t}\left[y_{t+1}\right]
$$

Here $i_{t}$ and $i^{\natural}$ denote the nominal interest rate and the natural interest rate, while $\pi_{t}$ and $y_{t}$ denote inflation and the output gap. The parameters satisfy $\sigma, \kappa \in(0, \infty)$ and $\beta \in(0,1)$. The expectation operators in (1) and (2) allow for the possibility of stochastic monetary policy.

Following the rest of the literature, we will rule out explosive solutions when solving this system of equations. However, we wish to point out that this standard assumption can be formally justified by requiring that the output gap always lies between finite lower and upper bounds, which we denote with $\hat{y}<0$ and $\check{y}>0$. We motivate the upper bound on $y_{t}$ with resource constraints: there is only so much that can be produced at one time from finite resources. The lower bound comes from Campbell (2016), who shows that price aggregation based upon CES preferences for differentiated goods imposes a lower bound on output. This

\footnotetext{
${ }^{2}$ See Galí (2008) for a derivation of these now-standard equations.

${ }^{3}$ In a stochastic environment, $m_{t}$ is sometimes called the "cost-push shock."
} 
equals output in a flexible-price economy with all firms currently unable to adjust their prices (and their goods) removed. Note that these upper and lower bounds can never be reached: households consume some leisure, and sticky-price firms continue producing. Therefore, we express them with strict inequalities, $\hat{y}<y_{t}<\check{y}$ for all $t$. Henceforth, we refer to these requirements on $y_{t}$ as the output feasibility constraints. In our analysis, these bounds eliminate from consideration otherwise-possible outcomes with either exploding or collapsing output. ${ }^{4}$ Moreover, they will not affect our analysis, so long as $m_{0}$ is small enough, as we will discuss below.

It is worth noting that having bounds on real output is more restrictive than requiring that expectations of real output are bounded. In particular, the latter assumption has the unappealing feature that it permits beliefs which are bounded because they include the possibility of infinite growth with some small probability.

As in Schaumburg and Tambalotti (2007), a sequence of central bankers sets monetary policy. The initial central banker, named 0 , faces a constant hazard of replacement each period, $\alpha$. If her term ends in period $t>0$, then central banker $t$ replaces her. She and all other central bankers face the same replacement hazard. A central banker at the beginning of her term chooses an infinite sequence of interest rates. For central banker $t$, we label these with $i_{t}^{t}, i_{t+1}^{t}, \ldots$. If central banker $t$ survives until period $t+j$, then the interest rate equals $i_{t+j}^{t}{ }^{5}$ Central bankers make no other choices, and they seek to minimize the same quadratic social loss function:

$$
\mathbb{E}_{0}\left[\sum_{t=0}^{\infty} \beta^{t}\left(\frac{1}{2} \pi_{t}^{2}+\frac{\lambda}{2} y_{t}^{2}\right)\right] .
$$

Denote inflation in period $t+j$ conditional on central banker $t$ being in power as $\pi_{t+j}^{t}$, so that $\pi_{t}^{t}$ is the inflation that will prevail in the first period of central banker $t$ 's term. Since $m_{t}=0$ for all $t \geq 1$, the social bliss point with $\pi_{t+j}^{t}=y_{t+j}^{t}=0$ for all $j \geq 0$ is consistent with the PCs and IS curves. Blanchard and Galí (2007) call this the "divine coincidence," so we refer to this outcome hereafter as the "divine coincidence outcome." We simplify this section's analysis by assuming that all central bankers except the first one successfully achieve it. In this case, the initial central banker's expected loss given her choices $\pi_{0+j}^{0}$ and

\footnotetext{
${ }^{4}$ The bounds on $y_{t}$ do not generate equilibrium determinacy by themselves, as can be demonstrated with a basic analysis of equilibrium determinacy using (1) with $m_{0}=0,(2)$, and a constant interest rate.

${ }^{5}$ The relevant extension of our model to a stochastic environment would have each central banker choosing state-contingent sequences of interest rates, $i_{t+j}^{t}\left(s^{t+j}\right)$, where $s^{t+j}$ gives the history of exogenous shocks up to and including $t+j$. The restriction to Markov strategies would require these to be only trivial functions of payoff-irrelevant portions of these histories.
} 
$y_{0+j}^{0}$ for all $j \geq 0$ is

$$
\sum_{j=0}^{\infty}(1-\alpha)^{j} \beta^{j}\left(\frac{1}{2}\left(\pi_{j}^{0}\right)^{2}+\frac{\lambda}{2}\left(y_{j}^{0}\right)^{2}\right) .
$$

The PCs and IS curves yield the following constraints on the initial central banker after taking expectations:

$$
\begin{aligned}
\pi_{j}^{0} & =\kappa y_{j}^{0}+\beta(1-\alpha) \pi_{j+1}^{0}+m_{j}, \\
y_{j}^{0} & =-\frac{1}{\sigma}\left(i_{j}^{0}-(1-\alpha) \pi_{j+1}^{0}-i^{\natural}\right)+(1-\alpha) y_{j+1}^{0} .
\end{aligned}
$$

Furthermore, the output feasibility constraints require

$$
y_{j}^{0} \in(\hat{y}, \check{y}) \forall j \geq 0
$$

The standard computational approach to similar Ramsey problems solves for optimal paths of inflation and the output gap constrained only by the PCs, and then backs out the required interest rates using the IS curves. This procedure applies here as well. The loss function and PCs only differ from their standard counterparts by a multiplicative discount factor adjustment, so one might (prematurely) conclude that quasi-commitment has no qualitative impact on the Ramsey planning problem. After all, the quasi-commitment solutions to this problem are just those of the perfect commitment problem with less patience. However, this is incorrect, because the same cannot be said of the IS curve (5). The change in the IS curve can eliminate the indeterminacy which plagues the standard model with perfect commitment.

To see how this is so, we follow Campbell and Weber (2019) and analyze this problem in terms of instruments instead of choices for inflation and output. Plug (4) into (5) to obtain a second order difference equation in terms of $\pi_{j}^{0}$ with the forcing function $x_{j}^{0} \equiv$ $-\frac{\kappa}{\sigma}\left(i_{j}^{0}-i^{\natural}\right)+m_{j}-(1-\alpha) m_{j+1}$,

$$
\pi_{j}^{0}-(1-\alpha)\left(1+\beta+\frac{\kappa}{\sigma}\right) \pi_{j+1}^{0}+\beta(1-\alpha)^{2} \pi_{j+2}^{0}=x_{j}^{0}
$$

Trivially, we can create a system with a unique solution by setting $\alpha$ to one. This would would leave the central banker with no ability to commit to future policy actions, as in Blake and Kirsanova (2012). On the other hand, if we set $\alpha$ to zero, (7) becomes the standard difference equation governing inflation with commitment to a completely passive monetary policy rule. This has a continuum of solutions. Does an intermediate case exist where the initial central banker can commit to future policy with some credibility, but the system still 
has a unique feasible solution given any bounded $\left\{x_{j}^{0}\right\}_{j=0}^{\infty}$ ?

To answer this in the affirmative, first note that the characteristic polynomial for (7) has roots equal to

$$
\psi, \varphi=\frac{\left(1+\beta+\frac{\kappa}{\sigma}\right) \pm \sqrt{\left(1+\beta+\frac{\kappa}{\sigma}\right)^{2}-4 \beta}}{2 \beta(1-\alpha)} .
$$

Label the roots so that $\psi>\varphi$. When $\alpha=0$, then $\psi>1 / \beta$ and $\varphi<1$. Obviously, both roots are increasing in $\alpha$. If

$$
\alpha>\alpha^{\star} \equiv \frac{-\left(1-\beta+\frac{\kappa}{\sigma}\right)+\sqrt{\left(1+\beta+\frac{\kappa}{\sigma}\right)^{2}-4 \beta}}{2 \beta}
$$

then $\varphi>1$. In this case, we can express the set of solutions to (7) as

$$
\pi_{j}^{0}=a_{0} \varphi^{j}+b_{0} \psi^{j}+\sum_{l=0}^{\infty} \varphi^{-l} \sum_{n=0}^{\infty} \psi^{-n} x_{j+n+l}^{0}
$$

Recall that the central bankers choices for $i_{t}^{0}-i^{\natural}$ determines $x_{t}^{0}$, along with the value of $m_{0}$. Thus, even if $m_{0}$ is small, extreme choices for $i_{t}^{0}-i^{\natural}$ might require $y_{t}^{0}$ to violate the output feasibility constraints. We impose an exogenous bound on these choices by bounding $x_{t}^{0}$

$$
\left|x_{t}^{0}\right|<\max \{-\hat{y}, \check{y}\} \frac{\kappa\left(1-\psi^{-1}\right)\left(1-\varphi^{-1}\right)}{1-\beta(1-\alpha)}
$$

This bound guarantees that the solution to (10) with $a_{0}=b_{0}=0$ satisfies the output feasibility constraints. All other solutions for $\pi_{j}^{0}$ diverge. There is nothing per se inadmissible about such paths for inflation, but when combined with the PCs they imply that the output gap's path conditional on the initial central banker remaining in office violates the output feasibility constraints. ${ }^{6}$ Thus, we have

Proposition 1. If $\alpha>\alpha^{\star}$ and, $\left\{x_{t}^{0}\right\}_{t=0}^{\infty}$ satisfies (11), then there exists exactly one pair of sequences for $\pi_{j}^{0}$ and $y_{j}^{0}$ which satisfy (4), (5) and (6). In this pair, $\pi_{j}^{0}$ is that from (10) with $a_{0}=b_{0}=0$.

Proposition 1 matters because it implies that the initial central banker can minimize her loss by solving her Ramsey problem, calculating the interest rates consistent with its solution and the IS curves, and announcing them as a deterministic path. ${ }^{7}$ This is a practical

\footnotetext{
${ }^{6}$ Note that the explosive solutions with $b_{0}=0$ and $a_{0} \neq 0$ do not display exploding paths for the expected output gap, because the explosion that occurs if the current central banker remains in office indefinitely is tempered by a very low probability of doing so.

${ }^{7}$ Since the initial central banker's optimal choices for $i_{t}^{0}-i^{\natural}$ are proportional to $m_{0}$, an appropriate bound on $m_{0}$ can guarantee (11).
} 
improvement upon the model with full commitment, which requires some means of coordinating private agents expectations upon the central banker's desired equilibrium (Campbell and Weber, 2019).

Qualitatively, replacing the model's interest rate rule with an optimizing central banker subject to quasi-commitment can eliminate the model's equilibrium multiplicity and thereby provide clearer guidance to real-world monetary policy makers. To assess its quantitative implications for the equilibrium set, consider the quarterly calibration of Schaumburg and Tambalotti (2007). Given their values of $\kappa=0.1, \beta=0.99$ and $\sigma=2 / 3 ; \alpha^{\star} \approx 0.32$. Since $\alpha^{-1}$ equals a central banker's expected tenure, her commitment to her forward guidance is expected to last about three quarters if $\alpha=\alpha^{\star}$. With any lower expected duration, we can apply Proposition 1 to show that the initial central banker can guarantee a unique outcome merely by choosing a path for interest rates.

Schaumburg and Tambalotti (2007) use a relatively high estimate of the PC's slope. Galí and Gertler (1999) estimate $\kappa=0.023$. Using this estimate for the slope, but holding the other parameters fixed yields $\alpha^{\star} \approx 0.17$, with a corresponding maximum expected duration of about six quarters. ${ }^{8}$ Eggertsson and Woodford (2003) set $\beta=0.99, \kappa=0.02$, and $\sigma=2$ for their numerical exercises. The resulting $\alpha^{\star}=0.0909$ gives a maximum average duration of forward guidance equal to eleven quarters. Figure 1 provides values of $\alpha^{\star}$ for each ratio $\kappa / \sigma \in[0,1 / 2]$, which covers most of the plausible ratios of empirical interest. It is easy to verify that $\alpha^{\star}$ always increases with $\kappa / \sigma$, as in the figure. ${ }^{9}$ By construction, $\alpha^{\star}=0$ if $\kappa=0$. Thus, Proposition 1 applies even when credibility is nearly perfect if the PC is very flat. Even if we use a high estimate for $\kappa$ such as the 0.1 from Schaumburg and Tambalotti (2007), and a low $\sigma$ of 0.2 (which corresponds to an intertemporal elasticity of substitution of 5 ), this would yield an $\alpha^{\star} \approx 1 / 2$. Bodenstein, Hebden, and Nunes (2012) estimate that for the U.S. in the recent period following the financial crisis, $\alpha$ was most likely above one half, with $\alpha \approx 0.6$ as a tentative point estimate. We conclude that quasi-commitment has quantitative promise for resolving the positive and normative problems that arise from the NK model's equilibrium indeterminacy.

\footnotetext{
${ }^{8}$ Galí and Gertler (1999) have an accompanying quarterly value of $\beta=0.942$. (See the estimated equation at the top of their page 207.) Lowering $\beta$ from 0.99 to this lower number makes practically no difference to our results.

${ }^{9}$ To develop intuition for this result, note that if $\kappa=0$, then (4) requires any bounded solution to satisfy $\pi_{t}^{0}=\pi_{t+1}^{0}=0$. Similarly, if $\sigma=\infty$, then (5) requires $y_{t}^{0}=y_{t+1}^{0}=0$ from bounded solutions. Equilibrium multiplicity only becomes possible by raising $\kappa$ or by lowering $\sigma$.
} 


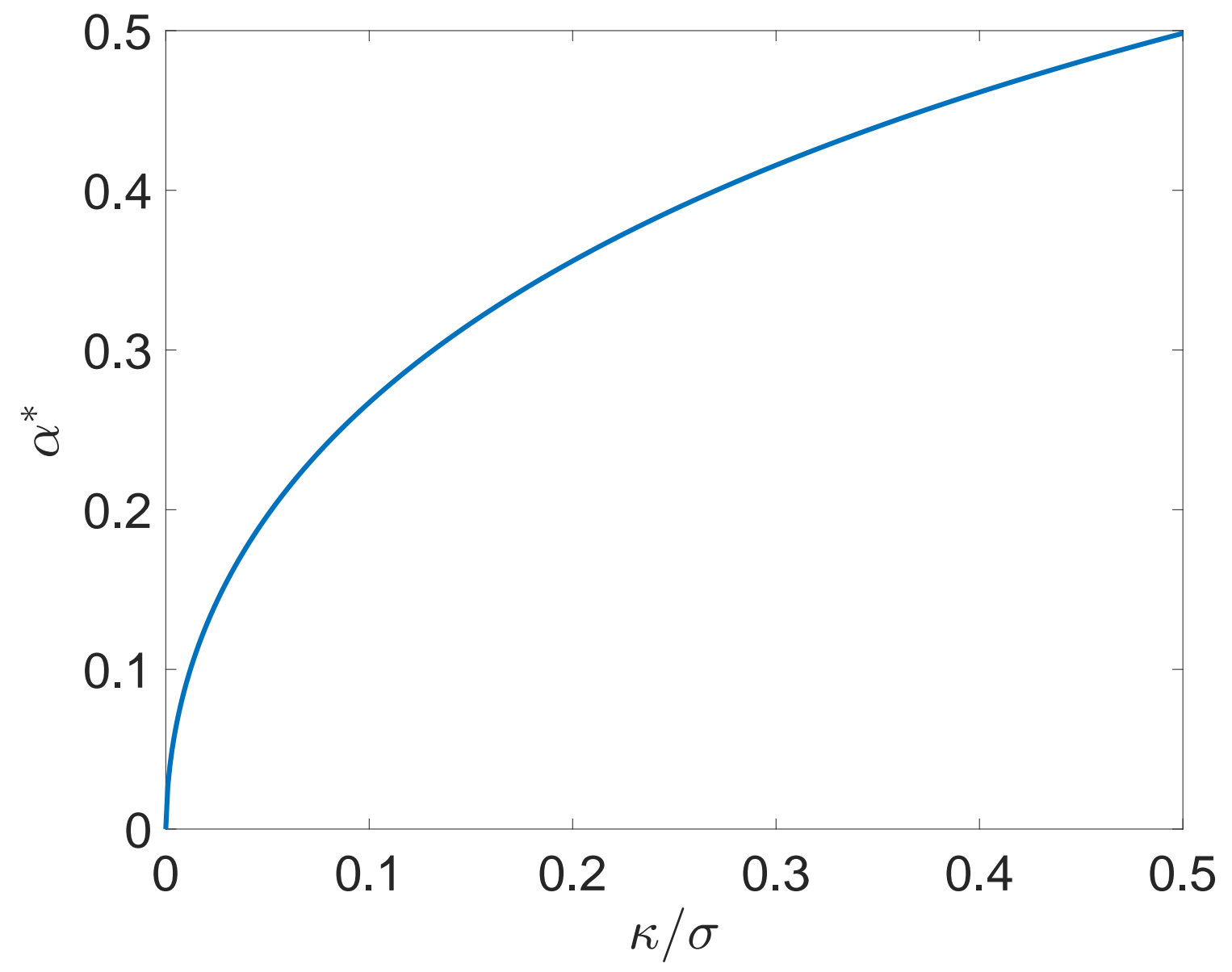

Figure 1: $\alpha^{\star}$ versus $\kappa / \sigma$ for $\beta=0.99$ 


\section{Quasi-Commitment Games}

This section endogenizes future central bankers' choices, relaxing the previous section's assumption that future central bankers implement the divine coincidence by demonstrating that this outcome is indeed the unique symmetric MPE of a game where each central banker controls only interest rates. We build toward this game - called the interest rate game by first developing a game where we allow central bankers to pick inflation and output outcomes, called the allocation game. We do this because the results obtained in the first game will aid our analysis of the second.

Specifically, in the allocation game, each central banker directly chooses the inflation and output sequences that will occur during her tenure constrained only by the sequence of PCs. This game is effectively the foundation of Debortoli and Lakdawala's (2016) empirical DSGE analysis. When $m_{0}$ is small enough so that our output feasibility constraints do not constrain any central bankers choices, this game has a unique symmetric Markov-perfect equilibrium (MPE) regardless of the frequency of central bankers' replacement. ${ }^{10}$

In the interest rate game, each central banker chooses a path of interest rates that will be set during her tenure, and the private sector chooses values for inflation and output each period. In this game, any private sector strategy that depends solely on the current and future interest rates promised by the current central banker and the remaining Phillipscurve intercepts can in principle be part of an MPE. We prove that this game has a unique symmetric MPE when the hazard of central banker replacement is high enough MPE by demonstrating that each central banker can uniquely implement her chosen outcome from the allocation game. Uniqueness then results from the fact that the allocation game has a unique symmetric MPE. The outcomes for inflation and output in the interest rate game are thus identical to the outcomes obtained in the unique symmetric MPE of the allocation game. Therefore, the results of Section 2 do not depend on the simplification of fixing economic outcomes after the initial central banker's tenure.

\subsection{The Allocation Game}

The initial central banker begins play by choosing sequences of inflation and output. So long as she is in office, these chosen sequences govern the realizations of actual inflation and output. She faces a constant probability of her term ending each period. If this occurs in period $t$, then central banker $t$ replaces her and makes her own choices of inflation and

\footnotetext{
${ }^{10}$ Blake and Kirsanova (2012) demonstrate that there exists a unique stationary Markov-perfect equilibrium in the special case of this game with $\alpha=1$. Our analysis builds on theirs by considering smaller values of $\alpha$. In turn, this requires confronting the possibility that the central bankers' interest rate choices might not uniquely determine economic outcomes during her tenure.
} 
output sequences. Her choices must satisfy the output feasibility constraints and the PCs taking her possible successors' choices as given:

$$
\pi_{t+j}^{t}=\kappa y_{t+j}^{t}+\beta(1-\alpha) \pi_{t+j+1}^{t}+\beta \alpha \pi_{t+j+1}^{t+j+1}+m_{t+j}
$$

Finally, all central bankers seek to minimize the common social-loss function given above. Since this game reduces to the Ramsey problem with perfect commitment when $\alpha=0$, we henceforth require $\alpha>0$.

In an MPE to this game, each central banker's choices depend only on current and future values of $m_{t}$; and in a symmetric MPE, two central bankers facing exactly the same future values of $m_{t}$ make the same choices. Since all central bankers but the initial one face the same constant sequence $m_{t}=0$, a symmetric MPE consists of two pairs of sequences: one for the initial central banker's choices of inflation and the output gap and one for all of her possible successors' choices.

Begin the allocation game's analysis by calculating successor central banker $t$ 's desired initial inflation rate, $\pi_{t}^{t}$, given the inflation rates that will prevail under all of her possible successors, $\pi_{t^{\prime}}^{t^{\prime}}$. Straightforward calculation yields the best-response curve

$$
\pi_{t}^{t}=\frac{\alpha \beta \theta}{\alpha \beta \theta+1-\beta \theta} \pi_{t^{\prime}}^{t^{\prime}}
$$

where $\theta \in(0,1)$ solves

$$
1-\left(1+\frac{\kappa^{2}}{\lambda}+\beta(1-\alpha)\right) \theta+\beta(1-\alpha) \theta^{2}=0
$$

Symmetry requires that $\pi_{t}^{t}=\pi_{t^{\prime}}^{t^{\prime}}$, and subgame perfection requires that each central banker plays a best response, so each central banker's initial inflation rate must equal the unique fixed point of (13), $\pi_{t}^{t}=0$. Given that all of central banker $t$ 's possible successors start their tenures with zero inflation, central banker $t$ can achieve zero inflation always. That is, $\pi_{t+j}^{t}=0$ for all $j \geq 0$. That is, each central banker will achieve the divine coincidence outcome during her tenure.

Given this necessary outcome, the initial central banker minimizes the loss function in (3) subject to the sequence of PCs in (4). Since this loss function is strictly convex and this constraint set is convex, the initial central banker's optimal choices are unique. It is not hard to show that these choices are proportional to $m_{0}$, so we can bound $m_{0}$ to ensure that the chosen output gaps satisfy the output feasibility constraints. The divine coincidence allocation implemented by all other central bankers satisfies these constraints automatically, 
so we have

Proposition 2. There exists an $\check{m} \in \mathbb{R}^{+}$such that if $\left|m_{0}\right|<\check{m}$, then the allocation game has one and only one MPE.

Even though we do not care about this game per se, the result is helpful for proving uniqueness in the interest rate game. Specifically, (13) demonstrates that optimal inflation for an incumbent central banker is a simple function of her replacement's initial inflation with a unique fixed point: the divine coincidence. If we can show that there is only one possible economic outcome during a central banker's tenure for any specific path of chosen interest rates, then the logic of subgame-perfect Nash equilibrium implies (13) is a necessary condition in any symmetric MPE of the interest rate game as well. Thus, the unique symmetric MPE of the interest rate game will have the same values for inflation and output as the much simpler game just presented.

The key to demonstrating that each central banker can implement their best response curve will in turn rest on showing that each central banker's choice of interest rate path has a unique outcome for inflation given the actions of future players. We now show below that this is indeed true when $\alpha>\alpha^{\star}$.

\subsection{The Interest Rate Game}

When $\alpha=1$, the current central banker and private agents take all future interest rates and macroeconomic outcomes as given. Therefore, the current central banker's single interest rate choice uniquely implements her chosen outcome. The connection between interest rates and macroeconomic outcomes can be looser when $\alpha<1$, so we examine next a game in which central bankers only control interest rates. For this, we add continua of infinitelylived households and firms, and we refer to these new players collectively as the "private sector." They inhabit the standard NK economy examined above, and their actions determine inflation and the output gap after any interest rate choices made by a central banker. Households derive utility from consumption and leisure, and firms seek to maximize their stock market values. Instead of providing detailed descriptions of these private objectives, we follow Atkeson, Chari, and Kehoe (2010) by requiring that the stochastic processes for $\pi_{t}$ and $y_{t}$ satisfy the sequences of PCs and IS curves.

All central bankers seek to minimize the same expected loss as in the allocation game. The initial central banker begins play by choosing and publicly announcing a sequence of interest rates that will prevail for as long as she is in office. We denote her choice for time $t$ with $i_{t}^{0}$. After setting this path, she makes no further choices. If her term ends at date 
$t$, central banker $t$ replaces her and makes her own once-and-for-all public choice of current and future interest rates, $i_{t}^{t}, i_{t+1}^{t}, i_{t+2}^{t}, \ldots$

A symmetric MPE for the interest-rate game collects four objects: an interest rate path for the initial central banker, another for all successor central bankers, and mappings from the continuation of the current central banker's interest rate path and the continuation of the sequence of PC intercepts into outcomes for the current inflation rate and output gap. These must jointly satisfy the PCs, the IS curves, and the output feasibility constraints for any possible interest rate path. Furthermore, the two chosen interest rate paths must minimize the expected loss for the initial and successor central bankers given the privatesector's mappings and the successor central bankers' common path.

Before proceeding with our analysis, we need to highlight a technical difficulty. First, if $\alpha \leq \alpha^{\star}$, then all of the sequences for $\pi_{t+j}^{t}$ and $y_{t+j}^{t}$ which satisfy the PCs and IS curves are backward looking. That is, $\pi_{t+j}^{t}$ and $y_{t+j}^{t}$ depend nontrivially on past interest rates, past PC intercepts and past expectations of inflation. This is because self-fulfilling prophecies require agents to believe that their own future behavior will depend on payoff-irrelevant variables. In this case, it is impossible to find mappings from the continuations of interest rates and PC intercepts into the current inflation rate and output gap. Therefore, we ensure that the set of private sector Markov strategies satisfying the PCs and IS curves is non-empty by henceforth requiring $\alpha>\alpha^{\star}{ }^{11}$

With this assumption in place, we may proceed with the interest rate game's equilibrium analysis. Our proof constructively establishes the existence of an MPE. It then demonstrates that the constructed MPE is unique.

Begin the construction by setting the initial central banker's interest rate path to that which satisfies the sequence of IS curves evaluated at her chosen inflation rates and output gaps in the allocation game's unique symmetric MPE. Second, do the same for succesor central bankers, setting the interest rate path to $i^{\natural}$ always for them. Third, set

$$
\pi_{t+j}^{t}=\sum_{l=0}^{\infty} \varphi^{-l} \sum_{n=0}^{\infty} \psi^{-n}\left(m_{t+j+n+l}-\frac{\kappa}{\sigma}\left(i_{t+j+n+l}^{t}-i^{\natural}\right)\right) .
$$

This is the appropriate generalization of (10) which describes the unique non-explosive solution to the PCs and IS curves consistent with all central bankers with names exceeding $t$ successfully implementing the divine-coincidence allocation (recall that for these successor central bankers, the term $m_{t+j+n+l}$ is always zero, so that (14) correctly evaluates to zero

\footnotetext{
${ }^{11}$ See Footnote 1 for a brief discussion of the model with exogenous term limits on central bankers, which always has a symmetric MPE.
} 
for a central banker with name $t \geq 1$ ). Fourth and finally, use the PCs to set

$$
y_{t+j}^{t}=\left(\pi_{t+j}^{t}-\beta(1-\alpha) \pi_{t+j+1}^{t}+\beta \alpha \pi_{t+j+1}^{t+j+1}\right) / \kappa
$$

We have now specified interest rates for the initial central banker (named 0), interest rate paths for all successor central bankers (with names $t \geq 1$ ), and mappings from central bank choices into private-sector outcomes for inflation described by (14), and for output described by (15) satisfying the requirements of Markov strategies. It remains to verify that this collection of strategies is subgame perfect.

To establish this, note that the successor central bankers' paths always achieve the divinecoincidence allocation. Therefore, all successor central bankers' choices minimize their expected losses, and none have an incentive to deviate. The initial central banker also achieves her minimum loss given her successors choices. Finally, the private sector mappings satisfy the PCs and IS curves by construction. Therefore, this collection forms one symmetric MPE.

To see that this is the only symmetric MPE, note that the PCs, the IS curves, and the output feasibility constraints together require that the following holds in every symmetric MPE for the interest rate game:

$$
\begin{aligned}
\pi_{t+j}^{t}= & \sum_{l=0}^{\infty} \varphi^{-l} \sum_{n=0}^{\infty} \psi^{-n}\left(m_{t+j+n+l}-\frac{\kappa}{\sigma}\left(i_{t+j+n+l}^{t}-i^{\natural}\right)\right) \\
& +\frac{\left(\alpha^{2} \beta+\alpha \kappa / \sigma\right) \pi_{t^{\prime}}^{t^{\prime}}+\alpha \kappa y_{t^{\prime}}^{t^{\prime}}}{1-(1-\alpha)(1+\beta+\kappa / \sigma)+\beta(1-\alpha)^{2}},
\end{aligned}
$$

where $\pi_{t^{\prime}}^{t^{\prime}}$ and $y_{t^{\prime}}^{t^{\prime}}$ equal all successor central bankers' common initial inflation rate and initial output gap. ${ }^{12}$ Equation (16) implies that there is one and only one inflation response from the private sector to any given interest rate path chosen by the current central banker. Therefore, each successor central banker can guarantee that the private sector implements her best response to $\pi_{t^{\prime}}^{t^{\prime}}$ by choosing the interest rates consistent with her Ramsey planning problem's solution. In turn, this implies that the best-response relationship (13) from the allocation game is a necessary condition for a symmetric MPE of the interest-rate game. This requires that $\pi_{t}^{t}=y_{t}^{t}=0$ for all $t \geq 1$. Since (16) also implies that the initial central banker can guarantee that the private sector implements her chosen outcome by setting the interest rates consistent with it, we have

Proposition 3. Given $\alpha>\alpha^{\star}$, there exists an $\check{m} \in \mathbb{R}^{+}$such that if $\left|m_{0}\right|<\check{m}$, then the interest rate game has one and only one MPE. Its outcomes equal those in the allocation

\footnotetext{
${ }^{12}$ Recall that $m_{t}=0$ for $t \geq 1$ by assumption. If instead future PC intercepts were nonzero, then the expression in (16) would require modification.
} 
game's unique MPE.

Proposition 3 demonstrates that equilibrium uniqueness is not simply an artifact of the Section 2's simplifying assumptions.

\subsection{Conclusion and Discussion of Economic Logic}

In the introduction, we argued that the basic logic of Nash equilibrium reduced the scope for self-fulfilling prophecies in the two equation model when central bankers face a sufficiently high rate of replacement. Here, we made this explicit.

We are not the first to note that if agents take outcomes in some possible states of the future as given while making choices today, the equilibrium determinacy in the NK model can be resolved when the probability of those states occurring is large enough. In particular, McKay, Nakamura, and Steinsson (2017) develop an illustrative model which results in a "discounted" IS curve of the following form:

$$
y_{t}=-\frac{\zeta}{\sigma}\left(i_{t}-\mathbb{E}_{t}\left[\pi_{t+1}\right]-i^{\natural}\right)+\chi \mathbb{E}_{t}\left[y_{t+1}\right] .
$$

where the "discounting" $\zeta, \chi<1$ results from the fact that agents optimize facing an i.i.d shock which will leave them "unemployed" (with idiosyncratic productivity of zero, specifically) and with a marginal utility which is fixed exogenously by lump-sum welfare benefits and liquidity constraints which prevent the unemployed from borrowing against their future income. Those authors show that the higher the probability of entering the state where agents take utility as given - in our context, $\alpha$ - the lower is $\chi$. As some of authors cited in our discussion of the discounted IS curve in the introduction show, a low enough $\chi$ will result in determinacy even with a completely passive interest rate rule. ${ }^{13}$ Thus, such a model of discounting arrives at a similar conclusion: only with a high enough probability of entering a state where outcomes are fixed with respect to current choices do we achieve determinacy.

\section{The Forward-Guidance Puzzle}

The interest rate game produces a unique prediction given values of its primitives. Moreover, that prediction conforms to the conventional, old-Keynesian wisdom that higher interest rates today lower contemporaneous inflation as seen in (16), arguably unlike in the cannonical NK model (Cochrane, 2017).

\footnotetext{
${ }^{13}$ See, for example, Gabaix (2018) or Michaillat and Saez (2019) for a similar discussion in a continuous time setting.
} 
Additionally, the model makes intuitive predictions about changes in long-dated forward guidance. Similar changes to forward guidance have challenged empirical DSGE models used at central banks (Del Negro, Giannoni, and Patterson, 2015). In those frameworks, a monetary authority promising a very small change to the policy rate delayed for a very long time can substantially influence current output and inflation. Furthermore, postponing the promise's implementation raises its effects on current outcomes. This is the forwardguidance puzzle of Carlstrom, Fuerst, and Paustian (2015). Studies of actual central bank forward guidance provide no evidence supporting this puzzling prediction (Campbell, Fisher, Justiniano, and Melosi, 2016). Moreover, the forward-guidance puzzle impedes applying the NK model to calculate appropriate future interest rate policy and to forecast economic outcomes conditional upon that policy's adoption, as FOMC participants do for the Survey of Economic Projections. ${ }^{14}$

In this section, we demonstrate that the quasi-commitment model with $\alpha>\alpha^{\star}$ lacks a forward-guidance puzzle. To see this, begin with the canonical model. With an active interest rate rule and $m_{t}=0 \forall t \geq 0$, the unique non-explosive equilibrium achieves the divine-coincidence allocation: $\pi_{t}=y_{t}=0$. Suppose that the central banker follows such an active interest rate rule on and after some date $\tau>0$, but the interest rate is pegged to an exogenous path $i_{0}, i_{1}, \ldots, i_{\tau-1}$ before then. Define the standard forward guidance experiment as a reduction of $i_{\tau-1}$ announced in period 0. Figure 2 reports the results of such an experiment using parameter values from Schaumburg and Tambalotti (2007). Here, $\tau=8$ and the interest rate is lowered five basis points in period 7. This has very modest contemporaneous effects on output and inflation, but the impacts on outcomes when the forward guidance is announced in period 0 exceed these by an order of magnitude. It is not hard to show analytically that the impacts of a given change in $i_{\tau-1}$ on $y_{0}$ and $\pi_{0}$ explode as $\tau \rightarrow \infty$.

The same forward-guidance experiment conducted under quasi-commitment comes out quite differently. Figure 3 plots the results for an experiment with the same parameter values used to construct Figure 2 but with $\alpha=0.4$. In this experiment, the initial central banker announces an arbitrary reduction of $i_{7}^{0}$ by $5 /(1-\alpha)^{7}$ basis points. By construction, this has the same impact on $\mathbb{E}\left[i_{7}\right]$ as a certain five basis point reduction. Here, the conditional expectations of inflation and output both increase as the date of forward-guidance implementation becomes closer. We can show analytically that the effects of a given announced change to $i_{\tau-1}^{0}$ on $y_{0}$ and $\pi_{0}$ go to zero as $\tau \rightarrow \infty$. Thus, the NK model with quasi-commitment can provide a framework for formulating optimal forward guidance without a forward-guidance puzzle. $^{15}$

\footnotetext{
${ }^{14}$ See Campbell and Weber (2019) for a brief but thorough exploration of this point.

${ }^{15}$ In a particular sense, this result arises directly from the initial central banker's limited commitment.
} 


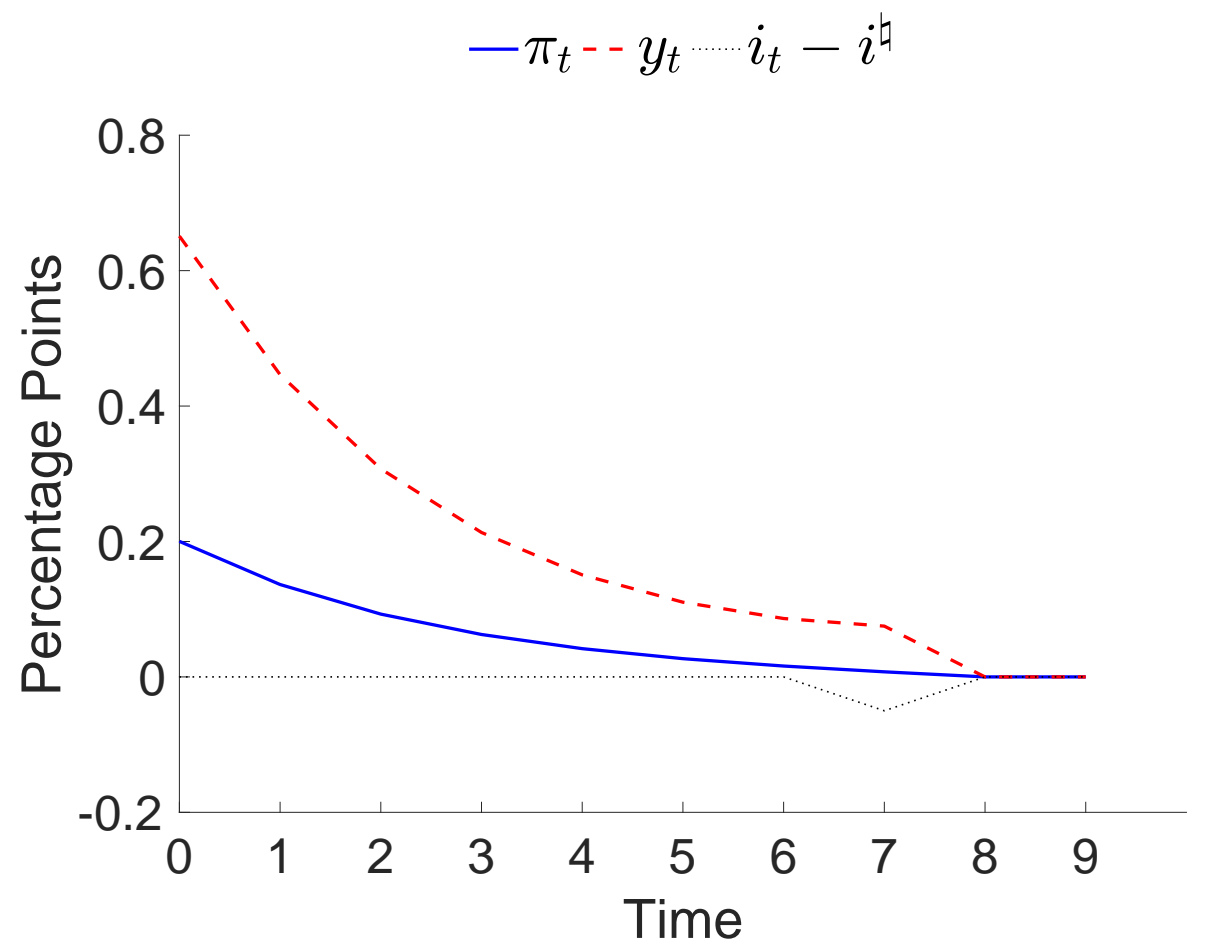

Figure 2: The Forward Guidance Puzzle 


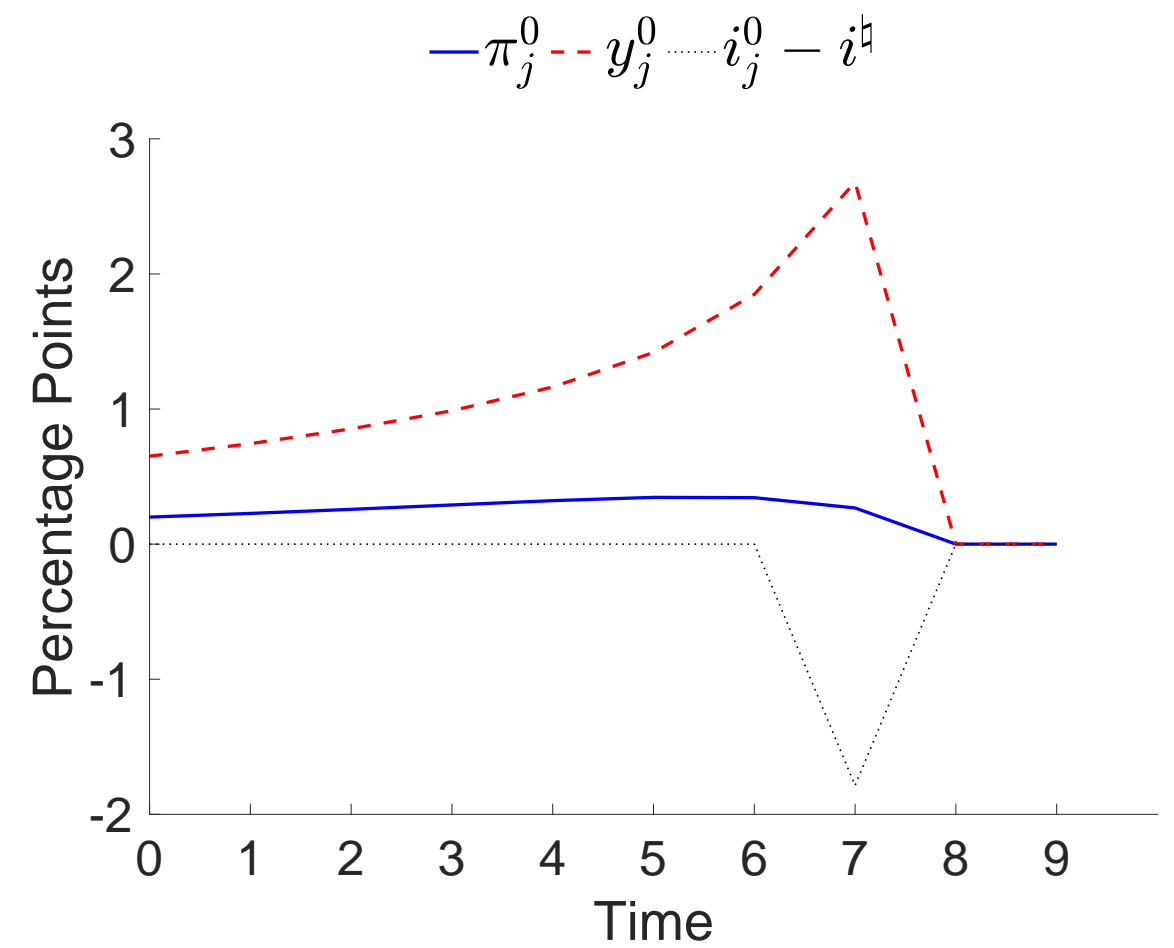

Figure 3: Forward Guidance with Quasi Commitment 


\section{$5 \quad$ Equilibrium Forward Guidance}

What sort of forward guidance does the initial central banker choose to offer in our setting when $m_{0} \neq 0$ ? In Figures 4 and 5, we illustrate the qualitative impact of imperfect credibility on the central banker's optimal promises and on the public's expectations. As in Section 2, the initial central banker faces a transitory non zero Phillips-curve intercept, here $m_{0}=1$, and $m_{t}=0$ for all $t \geq 1$. The colorful lines (dark when printed without color) give results under quasi-commitment, while the lighter, grey lines in each graph plot the solution with perfect commitment.

Figure 4 plots the initial central banker's optimal interest rate promises and the unique output and inflation sequence conditional on her remaining in office consistent with them. Since the quasi-commitment and full-commitment Ramsey problems differ only in their discount factor, the two allocations qualitatively resemble each other. Both prolong the initial recession and create a small but persistent disinflation which ultimately brings the economy's price level back to its original value. The most apparent quantitative difference between the two solutions appears in their interest rates. The initial central banker begins with a 56 basis point interest rate increase. The interest rate rises only 23 basis points in the corresponding full-commitment Ramsey plan. Mechanically, a given change in inflation expectations conditional on the initial central banker remaining in office has a smaller impact on current outcomes than does the same change announced by a planner with full commitment. This diminished effectiveness of forward guidance under quasi-commitment can be seen in the initial inflation rate and output gap. These exceed their counterparts from the full-commitment solution in magnitude, even though the central banker raises the interest rate more on impact. Imposing quasi-commitment has nearly no effect on the initial central banker's choice of future inflation. The increased discounting in the Phillips curve reflects a smaller impact of inflation promises on current price choices. Therefore, achieving this nearly invariant inflation sequence requires a deeper promised recession.

By construction, the central banker's loss is higher under quasi-commitment. Schaumburg and Tambalotti (2007) documented relatively small welfare losses from imperfect credibility under a wide range of loss functions and processes for $m_{t}$. With $\lambda=0.05$ and i.i.d. cost-push shocks, they found that quasi-commitment with $\alpha=1 / 2$ achieved approximately half of the gains of moving from complete discretion to complete commitment. If they de-

If we allow the promised interest rate change to grow as $\tau \rightarrow \infty$ so that the change in expected future interest rates is held constant, the forward-guidance puzzle reappears. Nevertheless, the inability of current central bankers to have arbitrarily large impacts on current macroeconomic outcomes without arbitrarily large promised changes to future interest rates makes the model with quasi-commitment more useful for the calculation of appropriate interest rate policy and its consequences. 
crease $\alpha$ to $1 / 3$, then they achieve 75 percent of these gains. ${ }^{16}$ In our deterministic economy with a one-time cost-push shock and $\alpha=0.4$, the initial central banker achieves 51 percent of the gains from perfect commitment.

Figure 5 plots the expected interest rates, inflation rates, and output gaps associated with both planning problems. As anticipated, agents expect inflation and the output gap to return to steady state much more quickly under quasi-commitment than under perfect commitment. Additionally, one qualitative difference stands out. While the initial central banker with quasi-commitment promises to bring the price level back to its original value, agents rationally expect the monetary authority (which includes the initial central banker's successors) to break this promise. That is, a central banker with quasi-commitment could be accurately described as implementing inflation targeting rather than price-level targeting. In this numerical example, the expected price-level reversion is quite modest. At the shock's impact, inflation and the price level both rise 73 basis points. The initial central banker's promise only undoes 20 basis points of this on average. We do not claim that this quantitative result characterizes more empirically-relevant specifications of the NK model, but it does illustrate Schaumburg and Tambalotti's (2007) finding that much of the gain from perfectly credible forward guidance can be achieved with a very imperfect commitment to price-level targeting.

\section{Conclusion}

The standard NK model provides no unique prediction for macroeconomic outcomes given a particular path of interest rates. In this paper, we have demonstrated that the quasicommitment NK model produces a unique prediction from a promised (but imperfectly credible) path for interest rates if the probability of monetary policy reoptimization is high enough. Thus, the model can be used for forecasting and for policy formation without assuming that central bankers can make incredible promises to follow active interest rate rules. Of course, there exist other well-known options for either eliminating or mitigating the forward guidance puzzle. Gabaix (2018) shows that introducing rationally inattentive households introduces a discounting of future outcomes in the IS curve very similar to that in (5). Angeletos and Lian (2016) and Barrdear (2017) mitigate the forward guidance puzzle by relaxing the assumption of common knowledge across agents, and Del Negro, Giannoni, and Patterson (2015) do so by introduce discounting of future outcomes in the IS curve with a perpetual youth lifecycle model. Our analysis complements these approaches by realistically relaxing the assumption of perfect monetary policy commitment. This requires no change

\footnotetext{
${ }^{16}$ Please see their Table 1.
} 


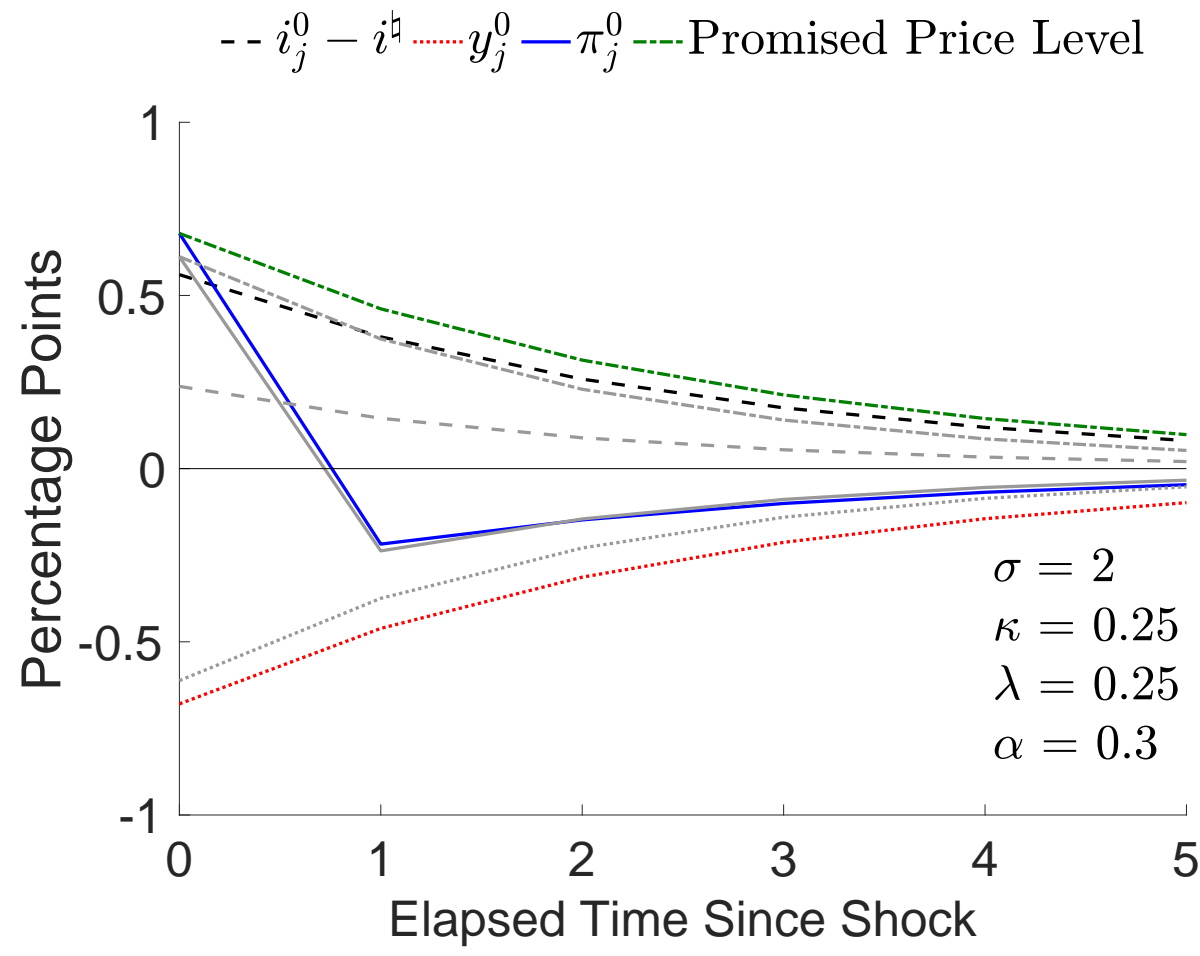

Figure 4: Central bank promises under quasi-commitment.

Note: Lighter, grey lines represent the perfect commitment solution. 
- - $\mathbf{E}_{0}\left[i_{t}-i^{\natural}\right] \cdots \cdots \mathbf{E}_{0}\left[y_{t}\right]-\mathbf{E}_{0}\left[\pi_{t}\right]$----Expected Price Level

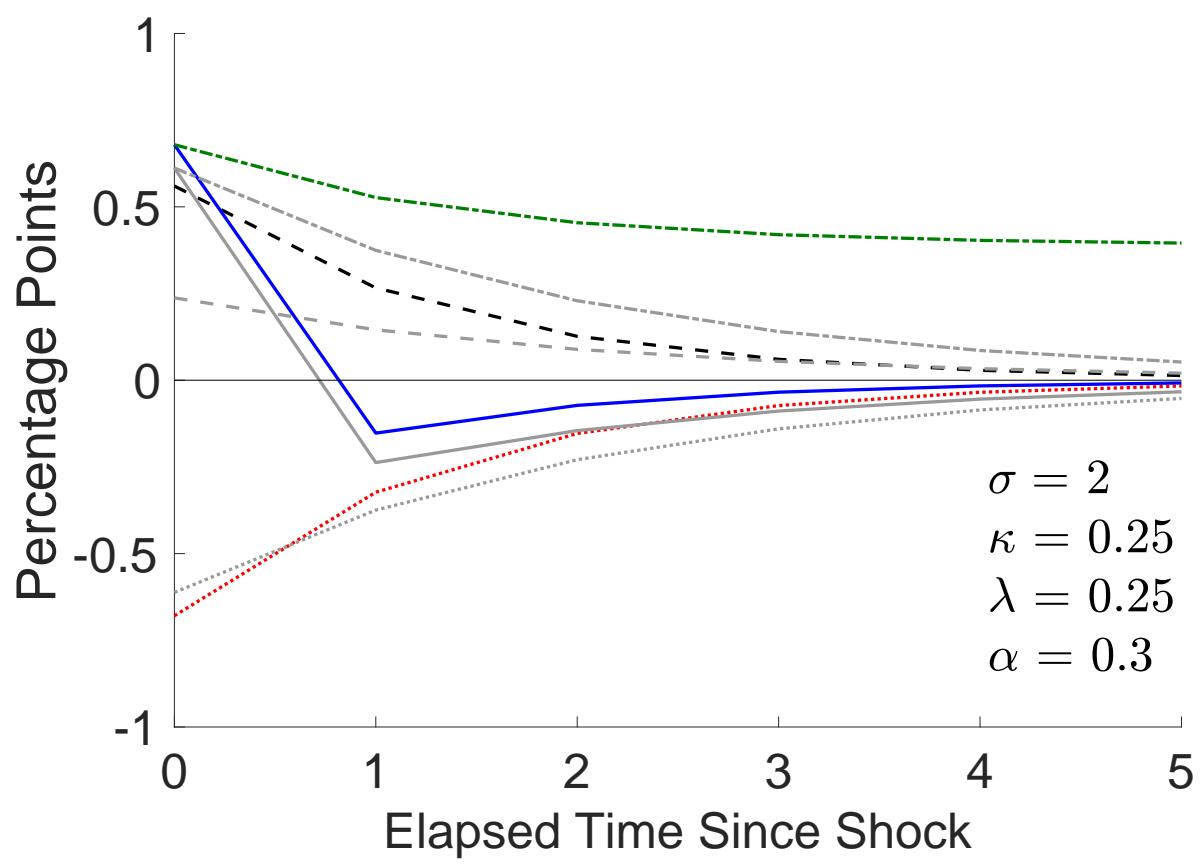

Figure 5: Agents' expectations under quasi-commitment.

Note: Lighter, grey lines represent the perfect commitment solution. 
to the standard model's market structure or information-processing technology.

Central bankers' interest in forward guidance rises substantially when the effective lower bound (ELB) constrains interest rates. For the special case with $\alpha=1$, Armenter (2016) demonstrates that our results do not immediately carry over to such an environment. Specifically, the ELB creates a second equilibrium reminiscent of the liquidity trap found by Benhabib, Schmitt-Grohé, and Uribe (2001) in the NK model with an active interest rate rule. A more thorough exploration of the quasi-commitment interest rate game with an ELB is on our research agenda. 


\section{References}

Adão, B., I. Correia, and P. Teles (2011). Unique monetary equilibria with interest rate rules. Review of Economic Dynamics 14(3), $432-442$.

Adão, B., I. Correia, and P. Teles (2014). Short and long interest rate targets. Journal of Monetary Economics 66, 95 - 107.

Angeletos, G.-M. and C. Lian (2016). Forward guidance without common knowledge. American Economic Review Forthcoming.

Armenter, R. (2008, August). A General Theory (and Some Evidence) of Expectation Traps in Monetary Policy. Journal of Money, Credit and Banking 40(5), 867-895.

Armenter, R. (2016). The Perils of Nominal Targets. Review of Economic Studies Forthcoming.

Atkeson, A., V. V. Chari, and P. J. Kehoe (2010). Sophisticated monetary policies. The Quarterly Journal of Economics 125(1), 47.

Barrdear, J. (2017). The calm policymaker. Bank of England Staff Working Paper 653.

Benhabib, J., S. Schmitt-Grohé, and M. Uribe (2001, January). The Perils of Taylor Rules. Journal of Economic Theory 96(1), 40-69.

Blake, A. P. and T. Kirsanova (2012, October). Discretionary Policy and Multiple Equilibria in LQ RE Models. The Review of Economic Studies 79(4), 1309-1339.

Blanchard, O. and J. Galí (2007). Real wage rigidities and the New Keynesian model. Journal of Money, Credit and Banking 39, 35-65.

Blinder, A. S. (1998). Central Banking in Theory and Practice. Cambridge, Massachusetts: MIT Press.

Bodenstein, M., J. Hebden, and R. Nunes (2012). Imperfect credibility and the zero lower bound. Journal of Monetary Economics 59(2), 135-149.

Campbell, J. R. (2016). Quantitative Easing in Joseph's Egypt with Keynesian Producers. Federal Reserve Bank of Chicago Working Paper 2014-15.

Campbell, J. R., C. L. Evans, J. D. Fisher, and A. Justiniano (2012). Macroeconomic Effects of Federal Reserve Forward Guidance. Brookings Papers on Economic Activity 1, 1-54. 
Campbell, J. R., J. D. Fisher, A. Justiniano, and L. Melosi (2016). Forward guidance and macroeconomic outcomes since the financial crisis. In NBER Macroeconomics Annual 2016, Volume 31, pp. 283-357. University of Chicago Press.

Campbell, J. R. and J. P. Weber (2019). Open mouth operations. Federal Reserve Bank of Chicago Working Paper 2018-03.

Carlstrom, C. T., T. S. Fuerst, and M. Paustian (2015, November). Inflation and output in New Keynesian models with a transient interest rate peg. Journal of Monetary Economics 76(C), 230-243.

Chang, R. (1998, August). Credible Monetary Policy in an Infinite Horizon Model: Recursive Approaches. Journal of Economic Theory 81, 431-461.

Chari, V., L. J. Christiano, and M. Eichenbaum (1998). Expectation Traps and Discretion. Journal of Economic Theory 81, 462-492.

Chari, V. and P. J. Kehoe (1990). Sustainable Plans. Journal of Political Economy 98(4), 783-802.

Cochrane, J. H. (2011). Determinacy and identification with Taylor rules. Journal of Political Economy 119(3), 565-615.

Cochrane, J. H. (2017, June). Michelson-Morley, Fisher, and Occam: The Radical Implications of Stable Quiet Inflation at the Zero Bound, pp. 113-226. University of Chicago Press.

Coibion, O. and Y. Gorodnichenko (2011, February). Monetary Policy, Trend Inflation, and the Great Moderation: An Alternative Interpretation. American Economic Review 101(1), $341-370$.

Debortoli, D. and A. Lakdawala (2016, July). How Credible Is the Federal Reserve? A Structural Estimation of Policy Re-Optimizations. American Economic Journal: Macroeconomics 8(3), 42-76.

Debortoli, D. and R. Nunes (2014, November). Monetary Regime Switches and Central Bank Preferences. Journal of Money, Credit and Banking 46(8), 1591-1625.

Del Negro, M., M. Giannoni, and C. Patterson (2015). The Forward Guidance Puzzle. Federal Reserve Bank of New York Staff Report 574. 
Eggertsson, G. and M. Woodford (2003). The Zero Interest-Rate Bound and Optimal Monetary Policy. Brookings Papers on Economic Activity 1, 139-211.

Fisher, J. D. (2015). On the structural interpretation of the Smets-Wouters "risk premium" shock. Journal of Money, Credit and Banking 47(2-3), 511-516.

Gabaix, X. (2018). A behavioral New Keynesian model. Unpublished Working Paper, Harvard University.

Galí, J. (2008). Monetary Policy, Inflation, and the Business Cycle: An Introduction to the New Keynesian Framework. Princeton, New Jersey, USA: Princeton University Press.

Galí, J. and M. Gertler (1999). Inflation dynamics: A structural econometric analysis. Journal of Monetary Economics 44(2), 195-222.

Haberis, A., R. Harrison, and M. Waldron (2014). Transitory interest-rate pegs under imperfect credibility.

King, R. G. and A. L. Wolman (2004, November). Monetary Discretion, Pricing Complementarity, and Dynamic Multiple Equilibria. Quarterly Journal of Economics 119(4), $1513-1553$.

Kocherlakota, N. R. (2016). Rules versus Discretion: A Reconsideration. Brookings Papers on Economic Activity 2016(Fall), 1-55.

McKay, A., E. Nakamura, and J. Steinsson (2017). The discounted Euler equation: A note. Economica 84(336), 820-831.

Michaillat, P. and E. Saez (2019). A New Keynesian model with wealth in the utility function. Manuscript, 34.

Phelan, C. and E. Stacchetti (2001). Sequential Equilibria in a Ramsey Tax Model. Econometrica $69(6), 1491-1518$.

Riboni, A. (2010, February). Committees as substitutes for commitment. International Economic Review 51(1), 213-236.

Riboni, A. and F. J. Ruge-Murcia (2010). Monetary policy by committee: Consensus, chairman dominance, or simple majority? The Quarterly Journal of Economics 125(1), $363-416$.

Roberds, W. (1987). Models of Policy under Stochastic Replanning. International Economic Review 28(3), 731-755. 
Romer, D. and J. Wolfers (2012). Comments and Discussion. Brookings Papers on Economic Activity 1, 74-80.

Ruge-Murcia, F. and A. Riboni (2017). Collective versus individual decision-making: A case study of the Bank of Israel Law. European Economic Review 93, 73 - 89.

Schaumburg, E. and A. Tambalotti (2007). An investigation of the gains from commitment in monetary policy. Journal of Monetary Economics 54(2), 302-324.

Siu, H. E. (2008, January). Time consistent monetary policy with endogenous price rigidity. Journal of Economic Theory 138(1), 184-210.

Stokey, N. L. (1991). Credible public policy. Journal of Economic Dynamics and Control 15, 627-656. 